\title{
Neonatal Anemia with Spontaneous Grade II Intra-ventricular Hemorrhage
}

\author{
Ghada Mahmoud Abdel-Rafee
}

\begin{abstract}
Department of Radiodiagnosis and Nuclear Medicine, Mansoura Health Insurance hospital, Egypt.

Correspondence to: Ghada Mahmoud Abdel-Rafee, Department of Radiodiagnosis and Nuclear Medicine, Mansoura Health Insurance hospital Egypt.
\end{abstract}

Email:

doctorghada2016@yahoo.com

Received: 2 May 2020

Accepted: 10 February 2021

\begin{abstract}
:
Background: Intra-ventricular hemorrhage (IVH), also known as intra-ventricular bleeding, is a bleeding into the brain's ventricular system, where the cerebrospinal fluid is produced and circulates through towards the subarachnoid space. It can result from physical trauma or from hemorrhaging in stroke. It is a significant finding in a neonatal intensive care incubator's babies with sudden onset of anemia. It attracts our attention to the importance of this issue $\&$ its burden complication in the future. Subject \& method: We report a case of full term male baby aged 10 days, delivered by caesarean section who was admitted to neonatal intensive care unit (NICU) with fits \& transient apnea. Bedside trans-cranial ultrasound is the main tool of investigation in NICU. Conventional therapy centers on managing hypertension and intracranial pressure while correcting coagulopathy and avoiding
\end{abstract} complications such as re-bleeding and hydrocephalus. Result: There is an association between neonatal anemia \& occurrence of spontaneous intra-ventricular hemorrhage. Conclusion: IVH may be a devastating complication of anemia \& bedside trans-cranial ultrasound is a valuable tool in detecting the degree of intra-ventricular hemorrhage and so patient outcome.

Keywords: Neonatal anemia, spontaneous, grade II, intra-ventricular hemorrhage.

\section{Introduction:}

Intra-ventricular extension of hemorrhage (IVH) is a particularly poor prognostic sign with expected mortality between $50 \%$ and 80\%.(1) Germinal matrix hemorrhage is a bleeding into the subependymal germinal matrix with or without subsequent rupture into the lateral ventricle. Such intraventricular hemorrhage can occur due to 
perinatal asphyxia in preterm neonates. (2) The germinal matrix is the site of proliferating neuronal and glial precursors in the developing brain, which is located above the caudate nucleus, in the floor of the lateral ventricle, and caudothalamic groove.

The germinal matrix contains a rich network of fragile thin-walled blood vessels, so that increased arterial blood pressure in these blood vessels leads to rupture and hemorrhage into germinal matrix. (3)

Primary IVH is confined to the ventricular system, arising from an intra-ventricular source or a lesion contiguous to the ventricles. Examples include intraventricular trauma, aneurysm, vascular malformation, and tumor, usually involving the choroid plexus. Approximately $70 \%$ of IVHs are secondary; secondary IVHs may occur as an extension of an intraparenchymal hemorrhage or SAH into the ventricular system. (4)

\section{Subject and method:}

A case report study was conducted in Mansoura Health Insurance Hospital in 1 to 5 May, 2020 time range. Written consent was taken from parents after home discharge for publication. Physical examination revealed abdominal distension, normal anterior fontanel \& normal Moro reflex. Laboratory investigation revealed hemoglobin level, normal glucose level, normal metabolites as sodium, potassium \& magnesium \& normal arterial blood gases.

\section{Results:}

Transcranial or transfontanellar ultrasound revealed: Grade II intra-ventricular hemorrhage (germinal matrix hemorrhage filling less than $50 \%$ of diameter of lateral ventricle \& seen in temporal horn only), no associated hydrocephalic changes, normal posterior fossa structures, normal deep periventricular white matter\& no midline shift (figure 1, 2).

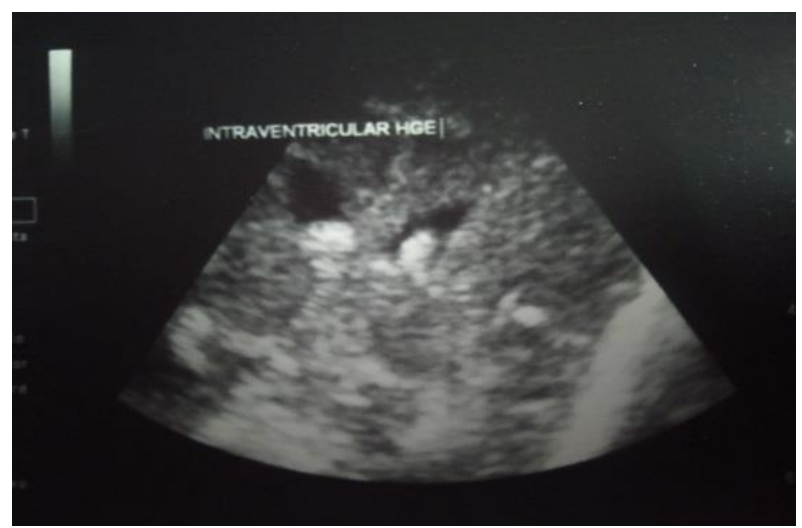

Figure (1): Trans-cranial ultrasound (coronal view) through the anterior fontanelle showed germinal matrix hemorrhage symmetrical on both sides $\&$ filling less than $50 \%$ of right \& left lateral horn. 


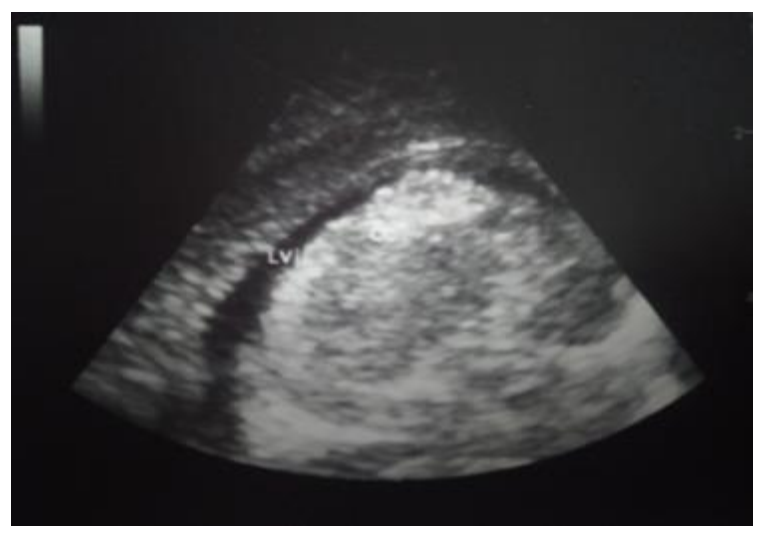

Figure (2): Trans-cranial ultrasound (sagittal view) through the anterior fontanelle showed germinal matrix hemorrhage symmetrical on both sides \& filling less than $50 \%$ of right $\&$ left lateral horn.

The Grab score is calculated by grading the lateral ventricles separately $(1=$ trace blood, 2 = less than half the ventricle filled with blood, $3=$ more than half the ventricle filled with blood, $4=$ ventricle filled with blood and expanded) and adding that sum to scores for the third and fourth ventricles, the maximum score is 12 . It is the most commonly reported scale in adults \& correlated significantly with short-term outcome (Tab.1). Bedside transcranial ultrasound is a valuable tool in delineation of the CNS complications associated with sudden onset of anemia. It is highly dedicated as first time diagnosis \& in follow up.

\section{table 1:}

\begin{tabular}{|c|c|c|c|c|c|c|c|c|}
\hline Blood \% & $\begin{array}{l}\text { Right } \\
\text { temporal } \\
\text { tip }\end{array}$ & $\begin{array}{l}\text { Right } \\
\text { lateral } \\
\text { horn } \\
\end{array}$ & $\begin{array}{l}\text { Right } \\
\text { occipital } \\
\text { horn }\end{array}$ & $\begin{array}{l}\text { Left } \\
\text { temporal } \\
\text { tip }\end{array}$ & $\begin{array}{l}\text { Left } \\
\text { lateral } \\
\text { horn } \\
\end{array}$ & $\begin{array}{l}\text { Left } \\
\text { occipital } \\
\text { horn }\end{array}$ & $\begin{array}{l}\text { Third } \\
\text { ventricle }\end{array}$ & $\begin{array}{l}\text { Fourth } \\
\text { ventricle }\end{array}$ \\
\hline None & 0 & 0 & 0 & 0 & 0 & 0 & 0 & 0 \\
\hline Less than $25 \%$ & 1 & 1 & 1 & 1 & 1 & 1 & 2 & 2 \\
\hline $25 \%-50 \%$ & 1 & 2 & 1 & 1 & 2 & 1 & 2 & 2 \\
\hline $50 \%-75 \%$ & 2 & 3 & 2 & 2 & 2 & 3 & 4 & 4 \\
\hline $75 \%-100 \%$ & 2 & 4 & 1 & 2 & 3 & 3 & 4 & 4 \\
\hline $\begin{array}{l}\text { Expanded } \\
\text { ventricle }\end{array}$ & +1 & +1 & +1 & +1 & +1 & +1 & +1 & +1 \\
\hline
\end{tabular}

\section{Discussion:}

Anemia is prevalent in neuro-critical disease \& is correlated with higher mortality in the intensive care units (5). Management of this case was packed red blood cells transfusion, anticonvulsant drugs \& fluid replacement. On follow up after one week, baby is improved clinically $\&$ transcranial ultrasound showed grade I 
IVH denoting regressive course of the disease. Post-hemorrhagic hydrocephalus (PHH) and periventricular leukomalacia (PVL) are two significant squeal of IVH. Patients with PHH usually present with rapidly increasing head circumferences, enlarging ventricles on radiologic examination and signs of increased intracranial pressure, but the signs and symptoms of hydrocephalus may not be evident for several weeks post-hemorrhage due to the compliance of neonatal brain. It is recommended to have ventricular puncture with removal of between 10 and $20 \mathrm{ml} / \mathrm{kg}$ of CSF for relieve of obstructive symptoms (6).

IVH can also result in white matter abnormalities, including periventricular leukomalacia (PVL). It is classically defined as multiple cystic foci in the periventricular cerebral white matter, which on histology demonstrate coagulation necrosis and loss of cellular architecture. It has been attributed to profound and longlasting decreases in cerebral blood flow that accompany the introduction of blood into the CSF. Some of these cases of PVL after IVH have also progressed to proencephaly. Depending on the severity and location of the PVL lesions, the clinical presentation of affected children may range from spastic diplegia to decreased visual fields and cognitive impairment. (7) The well-known sequelae of IVH have prompted the development of pharmacologic interventions as: phenobarbital, pavulon, vitamin E, ethamsylate, indomethacin, ibuprofen and recombinant activated factor VIIa. (8) Modified Rankin scale (mRS) is a clinical score that used to correlate degree of disability \& degree of functional outcome (Tab.2). We recorded "1" for study which adjusted for age, "2" adjusted for sex, "3" adjusted for ICH volume, "4" adjusted for IVH, "5" adjusted for drug use, "6" adjusted for NIHSS, "7" adjusted for transfusion, "8" adjusted for other vascular risk factors including coronary heart disease, congestive heart failure, atrial fibrillation, hypertension, hyperlipidemia \& DM (9).

Table (2): Modified Rankin score that correlate between the degree of disability \& the clinical outcome.

\begin{tabular}{|ll|}
\hline Supplementary Table 1: Modified Rankin Scale \\
\hline Score & Description \\
\hline 1 & $\begin{array}{l}\text { No symptoms at all. } \\
\text { No significant disability despite symptoms; able to } \\
\text { carry out all usual duties and activities. }\end{array}$ \\
\hline 2 & $\begin{array}{c}\text { Slight disability; unable to carry out all previous } \\
\text { activities, but able to look after own affairs without } \\
\text { assistance. }\end{array}$ \\
\hline 3 & $\begin{array}{c}\text { Moderate disability; requiring some help, but able to } \\
\text { walk without assistance. }\end{array}$ \\
\hline 4 & $\begin{array}{c}\text { Moderately severe disability; unable to walk without } \\
\text { assistance and unable to attend to own bodily needs } \\
\text { without assistance. }\end{array}$ \\
\hline 5 & $\begin{array}{c}\text { Severe disability; bedridden, incontinent and } \\
\text { requiring constant nursing care and attention. }\end{array}$ \\
\hline 6 & \begin{tabular}{l} 
Dead. \\
\hline Total $(0-6):$
\end{tabular} \\
\hline
\end{tabular}




\section{Conclusions:}

IVH may be a devastating complication associated with $\mathrm{ICH}$, predicting worsened morbidity \& mortality. Although conventional therapy has not made a dramatic impact on the natural history of the disease, several investigational techniques show promise in reducing the impact of IVH on recovery from $\mathrm{ICH}$.

\section{References:}

1. Coplin WM, Vinas FC \& Agris JM: A cohort study of the safety and feasibility of intra-ventricular urokinase for nonaneurysmal spontaneous intraventricular hemorrhage. Stroke (1998); 29 (8): 1573-1579, (PubMed: 9707195).

2. Enzmann D, Murphy-Irwin K, Stevenson D, Ariagno R, Barton J \& Sunshine P.: "The natural history of subependymal germinal matrix hemorrhage". Am J Perinatol. (1985); 2 (2): 123-33. doi:10.1055/s-2007-999929. PMID: 3913430.

3. Papile, Lu-Ann, Burstein, Jerome, Burstein \& Rochelle et.al. : "Incidence and evolution of subependymal and intraventricular hemorrhage: A study of infants with birth weights less than 1,500 gm". The Journal of Pediatrics. (1978); 92 (4): 529534. doi:10.1016/S0022-3476(78)80282-0. PMID: 305471 .

4. Steiner $\mathrm{T}$, Diringer $\mathrm{MN} \&$ Schneider D.: Dynamics of intra-ventricular hemorrhage in patients with spontaneous intra-cerebral hemorrhage: risk factors, clinical impact, and effect of hemostatic therapy with recombinant activated factor VII. Neurosurgery. (2006); 59(4):767-773. Discussion, (PubMed: 17038942).

5. Kramer AH, Zygun DA, Bleck TP, Dumont AS, Kassell NF \& Nathan B. et. al.: Relationship between hemoglobin concentrations and outcomes across subgroups of patients with aneurysmal subarachnoid hemorrhage. Neurocrit Care. (2009) 10:157-65. doi: 10.1007/s12028-008-9171-y.

6. Wellons J, Shannon C \& Oakes W.: Comparison of conversion rates from temporary CSF management to permanent shunting in premature IVH infants; The 36th Annual Meeting of the AANS/CNS Section on Pediatric Neurological Surgery; South Beach (Miami), Florida. p.35. [Google Scholar].

7. Bax M, Tydeman C \& Flodmark O.: Clinical and MRI correlates of cerebral palsy: the European Cerebral Palsy Study. Jama. (2006); 296:1602. [PubMed] [Google Scholar\}.

8. Whitelaw A. \& Odd D.: Postnatal phenobarbital for the prevention of intraventricular hemorrhage in preterm infants. Cochrane Database Syst. Rev. (2007); CD001691. [PubMed] [Google Scholar\}.

9. Barlas RS, Honney K, Loke YK, McCall SJ, Bettencourt-Silva JH \& Clark AB et al.: Impact of hemoglobin levels and anemia on mortality in:analysis of UK regional registry data, systematic review metaanalysis. J Am Heart Assoc. (2016) 5:e003019. doi: 10.1161/JAHA.115.003019.

To cite this article: Ghada Mahmoud Abdel-Rafee. Neonatal Anemia with Spontaneous Grade II Intra-ventricular Hemorrhage. BMFJ 2021; 38(Radiology):186-190. DOI: 10.21608 /bmfj. 2020. 29239.1255 